Portland State University

PDXScholar

\title{
Screening for Hepatitis C Virus Infection in
} Adolescents and Adults: Updated Evidence Report and Systematic Review for the US Preventive

\section{Services Task Force}

\author{
Roger Chou \\ Oregon Health \& Science University \\ Tracy Dana \\ Oregon Health \& Science University \\ Rongwei Fu \\ Oregon Health \& Science University \\ Bernadette Zahker \\ Oregon Health \& Science University \\ Jesse Wagner \\ Portland State University \\ Follow this and additional works at: https://pdxscholar.library.pdx.edu/sph_facpub \\ Part of the Infectious Disease Commons, and the Virus Diseases Commons

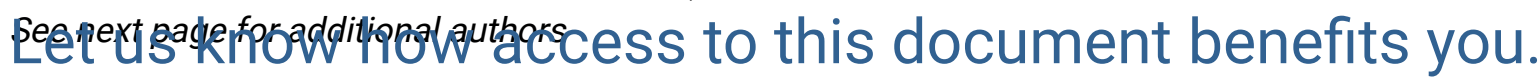

\section{Citation Details}

Chou, R., Dana, T., Fu, R., Zakher, B., Wagner, J., Ramirez, S., ... \& Jou, J. H. (2020). Screening for hepatitis C virus infection in adolescents and adults: updated evidence report and systematic review for the US Preventive Services Task Force. Jama, 323(10), 976-991.

This Article is brought to you for free and open access. It has been accepted for inclusion in OHSU-PSU School of Public Health Faculty Publications and Presentations by an authorized administrator of PDXScholar. Please contact us if we can make this document more accessible: pdxscholar@pdx.edu. 


\section{Authors}

Roger Chou, Tracy Dana, Rongwei Fu, Bernadette Zahker, Jesse Wagner, Shaun Ramirez, Sara Grusing, and Janice H. Jou 


\section{JAMA | US Preventive Services Task Force | EVIDENCE REPORT \\ Screening for Hepatitis C Virus Infection in Adolescents and Adults Updated Evidence Report and Systematic Review for the US Preventive Services Task Force}

Roger Chou, MD; Tracy Dana, MLS; Rongwei Fu, PhD; Bernadette Zakher, MBBS, MPH; Jesse Wagner, MA; Shaun Ramirez, MPH; Sara Grusing, BA; Janice H. Jou, MD, MHS

IMPORTANCE A 2013 review for the US Preventive Services Task Force (USPSTF) of hepatitis C virus (HCV) screening found interferon-based antiviral therapy associated with increased likelihood of sustained virologic response (SVR) and an association between achieving an SVR and improved clinical outcomes. New direct-acting antiviral (DAA) regimens are available.

OBJECTIVE To update the 2013 review on HCV screening to inform the USPSTF.

DATA SOURCES Ovid MEDLINE, the Cochrane Central Register of Controlled Trials, and the Cochrane Database of Systematic Reviews through February 2019, with surveillance through September 2019.

STUDY SELECTION Randomized clinical trials (RCTs) and nonrandomized treatment studies of HCV screening and DAA therapy; cohort studies on screening, antiviral therapy, and the association between an SVR after antiviral therapy and clinical outcomes.

DATA EXTRACTION AND SYNTHESIS One investigator abstracted data; a second checked accuracy. Two investigators independently rated study quality.

MAIN OUTCOMES AND MEASURES Mortality, morbidity, quality of life, screening and treatment harms, and screening diagnostic yield.

RESULTS Eight RCTS of DAA therapy vs placebo or an outdated antiviral regimen, 48 other treatment studies, and 33 cohort studies, with a total of 179230 participants, were included. No study evaluated effects of HCV screening vs no screening. One new study since the 2013 review ( $n=5917$ ) found similar diagnostic yield of risk-based screening (sensitivity, $82 \%$; number needed to screen to identify $1 \mathrm{HCV}$ case, 15) and birth cohort screening (sensitivity, $76 \%$; number needed to screen, 29), assuming perfect implementation. Ten open-label studies ( $n=3292$ ) reported small improvements in some quality-of-life and functional outcomes (eg, less than 3 points on the 0 to 100 36-Item Short Form Health Survey physical and mental component summary scales) after DAA treatment compared with before treatment. Two cohort studies $(n=24686)$ found inconsistent associations of antiviral therapy vs no therapy with risk of hepatocellular carcinoma. Forty-nine treatment studies ( $n=10181$ ) found DAA regimens associated with pooled SVR rates greater than $95 \%$ across genotypes, and low short-term rates of serious adverse events (1.9\%) and withdrawal due to adverse events (0.4\%). An SVR after antiviral therapy was associated with decreased adjusted risk of all-cause mortality (13 studies, $n=36986$; pooled hazard ratio [HR], 0.40 [95\% Cl, 0.28-0.56) and hepatocellular carcinoma (20 studies, $\mathrm{n}=84$ 491; pooled HR, 0.29 [95\% Cl, 0.23 to 0.38$]$ ) vs no SVR.

CONCLUSIONS AND RELEVANCE Direct evidence on the effects of HCV screening on clinical outcomes remains unavailable, but DAA regimens were associated with SVR rates greater than $95 \%$ and few short-term harms relative to older antiviral therapies. An SVR after antiviral therapy was associated with improved clinical outcomes compared with no SVR.

JAMA. 2020;323(10):976-992. doi:10.1001/jama.2019.20788 Published online March 2, 2020. Corrected on March 10, 2020
Editorial page 936

Related article page 970 and JAMA Patient Page page 1008

Audio and Supplemental content

Related articles at jamanetworkopen.com jamainternalmedicine.com
Author Affiliations: Pacific Northwest Evidence-based Practice Center, Department of Medical Informatics and Clinical Epidemiology, Oregon Health \& Science University, Portland (Chou, Dana, Fu, Zakher, Wagner, Ramirez, Grusing, Jou); Division of Genera Internal Medicine and Geriatrics, Oregon Health \& Science University, Portland (Chou); School of Public Health, Oregon Health \& Science University-Portland State University, Portland (Fu); Division of Gastroenterology and Hepatology, Oregon Health \& Science University, Portland (Jou)

Corresponding Author: Roger Chou, MD, Oregon Health \& Science University, 3181 SW Sam Jackson Park Rd, Mail Code BICC, Portland, OR 97239 (chour@ohsu.edu). 
I t has been estimated that from 2013 to 2016 approximately 4.1 million people in the US were hepatitis C virus (HCV) antibody-positive, indicating past exposure, and that of these, approximately 2.4 million had active infection. ${ }^{1}$ Persons born between 1945 and 1965 were estimated to account for approximately three-fourths of HCV infections. However, recent increases in acute HCV incidence have mostly affected young persons who inject drugs. ${ }^{2,3}$

In 2013, the US Preventive Services Task Force (USPSTF) recommended HCV screening for adults born between 1945 and 1965 ("birth cohort" screening) and those at high risk of infection (B recommendation). ${ }^{4}$ The recommendation was based on the effectiveness of then-current antiviral therapies with interferon. HCV treatment has subsequently evolved to direct-acting antiviral (DAA) regimens without interferon.

This evidence report was conducted to update the 2013 USPSTF review on HCV screening in adults ${ }^{5,6}$ and a comparative effectiveness review on antiviral treatments, ${ }^{7,8}$ to inform the USPSTF for an updated recommendation statement. This report focused on currently recommended DAA regimens and was expanded to include adolescents.

\section{Methods}

\section{Scope of the Review}

Detailed methods and evidence tables with additional study details are available in the full evidence report at https:// www.uspreventiveservicestaskforce.org/Page/Document/ UpdateSummaryFinal/hepatitis-c-screening1. Figure 1 shows the analytic framework and key questions (KQs) that guided the review. KQs on prenatal HCV screening (KQ $1 \mathrm{~b}$ ) and interventions to prevent vertical HCV transmission during labor and delivery (KQ5) are addressed in the full report.

\section{Data Sources and Searches}

Ovid MEDLINE, the Cochrane Central Register of Controlled Trials, and the Cochrane Database of Systematic Reviews were searched from 2013 through February 2019 (eMethods 1 in the Supplement). Searches were supplemented by reference list review of relevant systematic reviews; studies from the prior USPSTF review ${ }^{6,9}$ meeting inclusion criteria were carried forward. Ongoing surveillance was conducted to identify major studies published since February 2019 that may affect the conclusions or understanding of the evidence and the related USPSTF recommendation. The last surveillance was conducted on September 20, 2019, and identified no studies affecting review conclusions.

\section{Study Selection}

Two investigators independently reviewed titles, abstracts, and full-text articles using predefined eligibility criteria. The population for screening was asymptomatic adults and adolescents without prior HCV infection. For treatment, to evaluate patients more likely to be asymptomatic and identified by screening, inclusion was restricted to studies in which $20 \%$ or less of patients had cirrhosis at baseline ( $\leq 30 \%$ for cohort studies that controlled for fibrosis stage). Randomized clinical trials (RCTs) of screening and currently recommended DAA regimens vs placebo or an outdated antiviral regimen ${ }^{10}$ were included. Because of few randomized trials of DAA therapy vs placebo or an outdated antiviral regimen, nonrandomized clinical research treatment studies of DAA therapy (including those with a single group) and randomized trials that compared different DAA regimens were also included. The latter were classified as nonrandomized treatment studies rather than randomized trials in this review because data from relevant DAA regimens were analyzed separately (ie, the randomized comparison was not used). Cohort studies that controlled for potential confounders were included for screening; for associations of antiviral therapy (including older regimens) with mortality, hepatocellular carcinoma, and cirrhosis; and for the association between SVR after antiviral therapy and clinical outcomes. Outcomes were mortality, morbidity (eg, cirrhosis, hepatic decompensation, liver transplant, extrahepatic manifestations of HCV infection), quality of life, HCV transmission, sustained virologic response (SVR), harms, and screening yield (sensitivity and number of new diagnoses per test performed). Studies that focused on persons co-infected with HIV or hepatitis B virus, patients receiving transplants, and persons with advanced kidney disease were excluded.

\section{Data Abstraction and Quality Rating}

One investigator abstracted details about the study design, patient population, setting, interventions, analysis, followup, and results from each study. A second investigator reviewed abstracted data for accuracy. Two independent investigators assessed the quality of each study as good, fair, or poor using predefined criteria developed by the USPSTF (eMethods 2 in the Supplement). ${ }^{7}$ Discrepancies were resolved through a consensus process. In accordance with the USPSTF Procedure Manual, ${ }^{7}$ studies rated poor quality because of critical methodological limitations were excluded.

\section{Data Synthesis}

Random effects meta-analysis was performed to summarize the proportion of patients experiencing SVR and adverse events using a generalized linear mixed-effects model with a logit link. Analyses were stratified according to DAA regimen. For SVR, separate analyses were performed for each HCV genotype. A randomeffects (linear mixed-effects) meta-analysis was also performed on adjusted hazard ratios (HRs) for SVR after antiviral therapy vs no SVR and for clinical outcomes (mortality, liver-related mortality, cirrhosis, and hepatocellular carcinoma). If necessary, the adjusted HR for SVR vs no SVR was calculated from the adjusted HRs for SVR and no SVR vs no treatment. Statistical heterogeneity was assessed using the $R^{2}$ statistic. ${ }^{11}$

Subgroup analyses were conducted on geographic setting (US or Europe; multinational; other), fibrosis stage (cirrhosis excluded or some patients [up to $20 \%$ ] with cirrhosis), prior treatment status (naive or experienced to interferon-based therapies, boceprevir, or telaprevir), quality, and for cohort studies, full adjustment for key confounding variables (age, sex, fibrosis stage, and genotype). Stratified analyses were assessed for interactions using a test for heterogeneity across subgroups. For the association between DAA therapy and SVR rates, sensitivity analysis was performed by excluding studies in which ribavirin or dasabuvir 


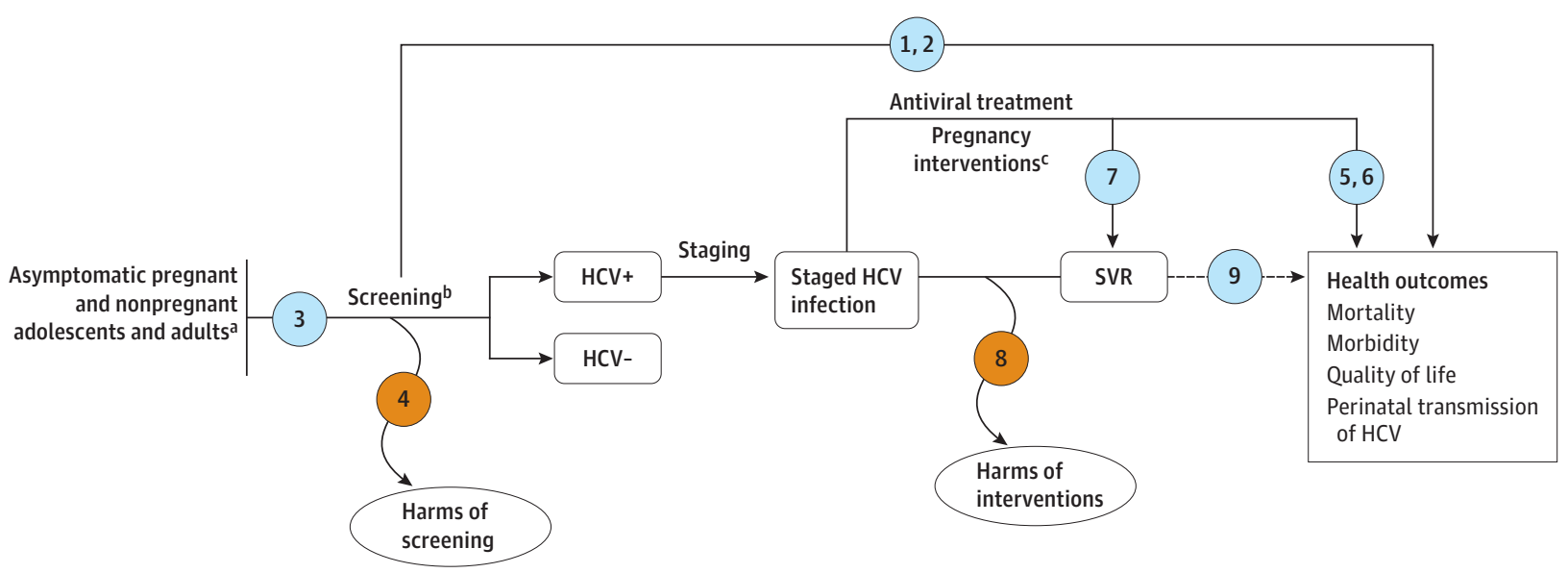

Key questions

1 a. Does screening for hepatitis C virus (HCV) infection in pregnant and nonpregnant adolescents and adults without known abnormal liver enzyme levels reduce HCV-related mortality and morbidity or affect quality of life?

b. Does prenatal screening for HCV infection reduce risk of vertical transmission of HCV infection? ${ }^{d}$

2 What is the effectiveness of different risk- or prevalence-based methods for screening for HCV infection on clinical outcomes?

3 What is the yield (number of new diagnoses per tests performed) of 1-time vs repeat screening or alternative screening strategies for HCV infection, and how does the screening yield vary in different risk groups?

4 What are the harms of screening for HCV infection (eg, anxiety and labeling)?

5 What are the effects of interventions during labor and delivery or the perinatal period on risk of vertical transmission of HCV infection?

6 What is the effectiveness of currently recommended antiviral treatments in improving health outcomes in patients with HCV infection?

7 What is the effectiveness of currently recommended antiviral treatments in achieving a sustained virologic response in patients with HCV infection?

8 What are the harms of currently recommended antiviral treatments?

9 What is the association between experiencing sustained virologic response following antiviral treatment and reduction in risk of HCV-related adverse health outcomes?

Evidence reviews for the US Preventive Services Task Force (USPSTF) use an analytic framework to visually display the key questions that the review will address to allow the USPSTF to evaluate the effectiveness and safety of a preventive service. The questions are depicted by linkages that relate interventions and outcomes. A dashed line indicates a health outcome that immediately follows an intermediate outcome. See USPSTF Procedure Manual. ${ }^{7} \mathrm{HCV}$ indicates hepatitis C virus; SVR, sustained virologic response.

${ }^{a}$ Includes persons without abnormal laboratory values. Adolescents are defined as those aged 12 to 17 years. Excludes persons living with HIV, transplant recipients, and patients with renal failure.

${ }^{b}$ Defined as HCV antibody testing with confirmatory HCV RNA testing as indicated.

${ }^{\mathrm{c}}$ Includes interventions that may affect vertical transmission of HCV, such as cesarean delivery, amniocentesis, fetal monitoring, management of ruptured membranes, breastfeeding, and antiviral treatment.

${ }^{\mathrm{d}}$ Addressed in the full evidence report. was not used as recommended. For the association between SVR vs no SVR after antiviral therapy and clinical outcomes, sensitivity analysis was performed by excluding cohort studies with potentially overlapping populations to ensure that results were not sensitive to double counting of patients. For analyses of harms, trials of ribavirin-containing regimens were excluded except for ombitasvir/paritaprevir/ritonavir/dasabuvir, which is recommended for genotype $1 \mathrm{~b}$ infection.

Meta-analyses were conducted using SAS version 9.4 (SAS Institute Inc) and RevMan version 5.3.5 (Nordic Cochrane Centre), and 
forest plots were created using Stata/SE version 14.0 (StataCorp). All significance testing was 2 -tailed; $P<.05$ was considered statistically significant.

\section{Results}

Across all KQs addressed in this article, 8 ( $n=3397$ ) RCTs (in 6 publications), ${ }^{12-17} 48(\mathrm{n}=7132)$ nonrandomized treatment studies (in 45 publications), ${ }^{18-62} 33$ ( $n=168701$ ) cohort studies, ${ }^{63-95}$ 2 additional pooled analyses, ${ }^{96,97}$ and 1 retrospective study $(n=5917)^{98}$ on the yield of alternative screening strategies in a cohort of patients in a national survey were included (Figure 2). Eighty-three studies ${ }^{12-62,64,66-74,77,79,81-83,85-92,95-98}$ were new for this update, and $963,65,75,76,78,80,84,93,94$ were carried forward from the previous USPSTF review.

\section{Benefits of Screening}

Key Question 1a. Does screening for HCV infection in pregnant and nonpregnant adolescents and adults without known abnormal liver enzyme levels reduce HCV-related mortality and morbidity or affect quality of life?

No study met inclusion criteria for this $\mathrm{KQ}$.

Key Question 2. What is the effectiveness of different riskor prevalence-based methods for screening for HCV infection on clinical outcomes?

No study met inclusion criteria for this $\mathrm{KQ}$.

Key Question 3. What is the yield (number of new diagnoses per tests performed) of 1-time vs repeat screening or alternative screening strategies for HCV infection, and how does the screening yield vary in different risk groups?

A retrospective study ( $n=5917$ ) compared the yield of risk-based HCV screening vs birth cohort screening in a cohort of patients sampled from the National Health and Nutrition Examination Survey. ${ }^{98}$ It found that applying risk-based guidelines perfectly would screen $24.7 \%$ of the US general population and identify $82 \%$ of HCV cases, with a number needed to screen to identify $1 \mathrm{HCV}$ case of 14.6. Applying the birth cohort strategy would screen $45 \%$ of the general population and identify $76 \%$ of cases, with a number needed to screen of 28.7 . No study evaluated the yield of 1-time vs repeat screening, the yield of alternative screening strategies in different risk groups, or the yield of currently recommended screening vs expanded screening strategies.

\section{Harms of Screening}

Key Question 4. What are the harms of screening for HCV infection (eg, anxiety and labeling)?

No study compared harms of HCV screening vs no screening. Poor-quality evidence from the prior USPSTF review suggested potential negative psychological and social effects of screening but was uncontrolled and did not meet inclusion criteria for this update.

\section{Benefits of Treatment}

Key Question 6. What is the effectiveness of currently recommended antiviral treatments in improving health outcomes in patients with HCV infection?
Adults

Quality of Life/Function I Ten open-label treatment studies ( $n=2404$ ) reported quality-of-life and functional outcomes before and after receipt of current DAA regimens (eTable 1 in the Supplement). Seven studies were included in 2 pooled analyses, ${ }^{95,96}$ and there were 3 additional studies (reported in 2 publications). ${ }^{12,99}$

At 12 weeks after treatment, 2 pooled analyses found sofosbuvir/velpatasvir (4 trials) or sofosbuvir/ledispavir (3 trials) associated with improvements in some measures of quality of life or function compared with before treatment, though differences were small (eg, less than 3 points on the 36-Item Short Form Health Survey physical and mental component summary scales [range, 0-100 points] or 0.04 to 0.05 points on the 6-Dimensional Health State Form health utility scale), and not all differences were statistically significant. ${ }^{95,96}$ Results were similar in 2 studies of ombitasvir/paritaprevir/ritonavir/dasabuvir ${ }^{12}$ or elbasvir/grazoprevir. ${ }^{99}$

Mortality | Thirty-one treatment studies (in 28 publications; $n=3848$ ) reported mortality at 12 to 36 weeks after completion of DAA therapy but were not designed to assess this outcome. $^{14-19,24,25,27,28,30-32,36,37,39,41-44,46,48,49,51-55}$ Twenty-one studies reported no deaths, and the remaining 10 studies reported 17 deaths ( $0.4 \%$ overall. Ten deaths occurred in 3 studies of persons reporting recent injection drug use or use of opioid substitution therapy. $31,32,55$

Other Clinical Outcomes | Three cohort studies ( $n=58$ 892) evaluated other clinical outcomes (eTable 2 in the Supplement). ${ }^{67,68,83}$ Follow-up ranged from 1.1 to 7.4 years. One study found DAA therapy, vs interferon-based therapy or antiviral therapy, was associated with decreased risk of cardiovascular events, including acute myocardial infarction, congestive heart failure, and stroke (incidence rate per 1000 person-years of follow-up, 16.3 [ $95 \% \mathrm{Cl}, 14.7$ to 18.0] for DAA therapy; 23.5 [95\% Cl, 21.8 to 25.3 ] for interferon-based therapy; and 30.4 [ $95 \% \mathrm{Cl}, 29.2$ to 31.7 ] for no therapy; $P<.001$ for antiviral therapy vs no therapy). ${ }^{67}$ One study found DAA and interferonbased therapy associated with similar incidence of hepatocellular carcinoma that was lower than with no antiviral therapy (incidence rate per 1000 person-years, $7.5[95 \% \mathrm{Cl}, 6.5$ to 8.6$]$ and $7.9[95 \% \mathrm{Cl}, 6.0$ to 10.4] for antiviral therapy and 10.9 [95\% Cl, 9.92 to 11.97] for no therapy; $P$ value not reported). ${ }^{83}$ The third study found no difference between DAA therapy vs no antiviral therapy in risk of hepatocellular carcinoma (adjusted $\mathrm{HR}, 1.02$ [95\% Cl, 0.40 to 2.61]); point estimates for associations with all-cause mortality favored DAA therapy, but the difference was not statistically significant (adjusted $\mathrm{HR}, 0.74$ [95\% Cl, 0.43 to 1.28$]) .{ }^{68}$

\section{Adolescents}

Three treatment studies of adolescents $(n=200)$ reported changes of 2 to 13 points on Pediatric Quality of Life Inventory (scale, 0-100) scores after treatment with DAA therapy compared with baseline; effects were not always statistically significant (eTable 3 in the Supplement). ${ }^{59,61,100}$ Treatment studies of DAA therapy in adolescents were not designed to evaluate mortality (no deaths in 3 studies) ${ }^{57,61,62}$ or long-term clinical outcomes. 


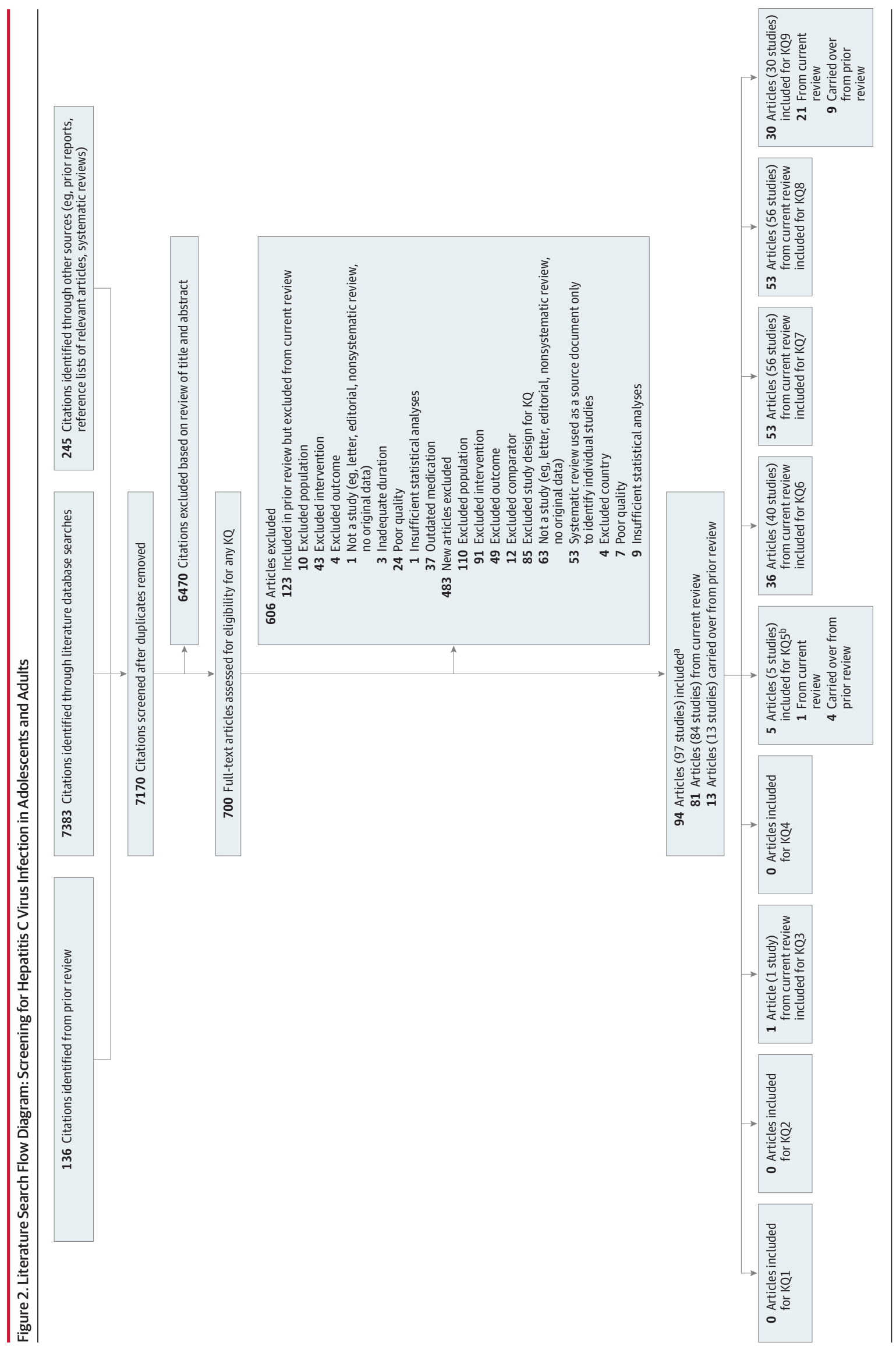


Key Question 7. What is the effectiveness of currently recommended antiviral treatments in achieving an SVR in patients with HCV infection?

\section{Adults}

Forty-nine studies (in 44 publications; $n=10181$ ) reported effects of current DAA treatment regimens on SVR in patients with HCV infection. ${ }^{12-55}$ SVR was measured 12 weeks after the completion of therapy in all studies except for 1 , which measured SVR at 14 weeks. Sample sizes ranged from 20 to 706 , mean age ranged from 45 to 68 years, and the proportion of women ranged from $18 \%$ to $64 \%$; the studies evaluated 7 different antiviral regimens (eTable 4 in the Supplement). One study was a randomized trial that compared a current DAA regimen vs placebo, ${ }^{14} 2$ randomized trials (reported in 1 publication) compared a current DAA regimen vs a regimen with telaprevir, ${ }^{12}$ and 2 randomized trials (reported in 1 publication) compared a current vs older DAA regimen. ${ }^{15}$ The other treatment studies did not compare a current DAA regimen vs placebo or an older regimen.

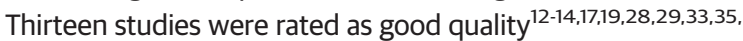
$36,46,51,54$ and the remainder as fair quality (eTable 5 in the Supplement). Methodological limitations included unclear randomization or enrollment methods. Loss to follow-up was low (range, 0\%-3\%). All of the trials were industry-funded.

SVR Rates in Comparative Trials | Few studies compared DAA interventions with placebo or older interventions (eTable 5 in the Supplement). One randomized trial found sofosbuvir/velpatasvir associated with very high likelihood of SVR vs placebo in persons with mixedgenotype $(1,2,4,5$, or 6 ) infection (99\% vs 0\%; relative risk [RR], 231.6 [95\% Cl, 14.6 to 3680]). ${ }^{14}$ Two randomized trials found ombitasvir/ paritaprevir/ritonavir/dasabuvir (with or without ribavirin) associated with increased likelihood of SVR vs telaprevir/pegylated interferon/ribavirin in treatment-naive persons with genotype 1 infection ( $98 \%$ vs $80 \%$; RR, 1.22 [95\% Cl, 1.08 to 1.37]) or persons previously treated with interferon therapy ( $99 \%$ vs $66 \%$; RR, 1.50 [95\% Cl, 1.22 to 1.85$]) .{ }^{12}$ Two randomized trials found sofosbuvir/velpatasvir for 12 weeks associated with increased likelihood of SVR vs sofosbuvir/ ribavirin for 24 weeks for genotype 2 (99\% vs 94\%; RR, 1.06 [95\% $\mathrm{Cl}, 1.01$ to 1.11]) and for genotype 3 infection (noncirrhosis subgroup, $97 \%$ vs $87 \%$; RR, 1.11 [95\% $\mathrm{Cl}, 1.05$ to 1.18$]$ ). ${ }^{15}$

Pooled SVR Rates | For genotype 1 HCV infection, the most common genotype in the US, DAA therapy was associated with a pooled SVR rate of $97.7 \%\left(95 \% \mathrm{Cl}, 96.6 \%\right.$ to $\left.98.4 \% ; I^{2}=82 \%\right)$ based on 32 studies ( $n=6055)$ (Figure 3 ). Evidence for genotypes 2 through 6 was more limited, ranging from 75 to 742 participants per genotype (eTable 7 in the Supplement). The pooled SVR rates ranged from 95.5\% to $98.9 \%$; for other common US genotypes, the pooled SVR was $98.9 \%\left(95 \% \mathrm{Cl}, 97.5 \%\right.$ to $\left.99.5 \% ; l^{2}=4 \%\right)$ for genotype 2 (5 studies, $\mathrm{n}=526)$ (eFigure 1 in the Supplement), $95.5 \%(95 \% \mathrm{Cl}$, $91.6 \%$ to $97.7 \% ; I^{2}=66 \%$ ) for genotype 3 ( 6 studies, $n=742$ ) (eFigure 2 in the Supplement), and $98.2 \%(95 \% \mathrm{Cl}, 94.7 \%$ to $99.4 \%$; $R^{2}=50 \%$ ) for genotype 4 (10 studies, $n=485$ ) (eFigure 3 in the Supplement). Across genotypes, SVR estimates were consistent when studies were stratified according to study quality, geographic setting, prior HCV treatment, inclusion of some patients with cirrhosis at baseline, and use of ribavirin as recommended (eTable 7 in the Supplement).

\section{Adolescents}

Seven studies ( $n=348$ ) evaluated the effects of DAA regimens on SVR in adolescents (eTable 8 in the Supplement). ${ }^{56-62}$ Mean age ranged from 12 to 15 years, and the proportion of female participants ranged from $35 \%$ to $66 \%$. Three of the 7 studies were conducted in Egypt and focused on genotype 4 infection, 1 study enrolled patients with genotype 1 , and 3 studies enrolled mixed genotypes. Four studies evaluated DAA regimens approved by the US Food and Drug Administration (FDA) for use in adolescents, ${ }^{57-59,61}$ and the others evaluated DAA regimens recommended for adults but not FDA-approved for adolescents. ${ }^{56,60,62}$ Across all intervention studies of DAA in adolescents, the SVR rate ranged from $97 \%$ to $100 \%$.

\section{Harms of Treatment}

Key Question 8. What are the harms of currently recommended antiviral treatments?

Adults

Forty-nine treatment studies (in 44 publications; $n=10$ 181) of DAA regimens without interferon reported the proportion of patients who experienced adverse events at short-term follow-up (ie, while taking antiviral therapy through up to 12 weeks after completion of therapy). ${ }^{12-55}$

Adverse Events in Comparative Trials | Four randomized trials (total $n=2113$ ) reported adverse events associated with current DAA regimens vs placebo (eTable 9 in the Supplement). ${ }^{13,14,16,17}$ DAA regimens were associated with slightly increased risk of any adverse event (4 trials; RR, 1.12 [95\% Cl, 1.02 to 1.24$]$; $l^{2}=46 \%$; absolute risk difference [ARD], 8\% [95\% Cl, 8\% to 15\%]) (eTable 9 in the Supplement). DAA therapy was also associated with increased risk of nausea (3 trials; RR, 1.42 [95\% Cl, 1.00 to 2.03]; $I^{2}=10 \%$; ARD, 4\% [95\% $\mathrm{Cl},-3 \%$ to $10 \%]$ ); the association with increased risk of diarrhea was not statistically significant ( 2 trials; $R R, 1.53$ [95\% Cl, 0.88 to 2.68]; $R^{2}=29 \%$ ). There were no differences between DAA regimens vs placebo in risk of serious adverse events, withdrawal due to adverse events, headache, or fatigue.

Two randomized trials (reported in 1 publication; $n=457$ ) compared a DAA regimen (ombitasvir/paritaprevir/ritonavir/dasabuvir with or without ribavirin) vs telaprevir/pegylated interferon/ ribavirin for genotype 1 infection (eTable 10 in the Supplement). ${ }^{12}$ DAA therapy was associated with decreased risk of serious adverse events (RR, 0.08 [95\% Cl, 0.02 to 0.34]; $l^{2}=0 \%$; ARD, -8\% [95\% $\mathrm{Cl},-15 \%$ to $-1 \%]$ ) and withdrawal due to adverse events (RR, 0.06 [95\% Cl, 0.01 to 0.29]; $l^{2}=0 \%$; ARD, $-9 \%$ [95\% Cl, $-14 \%$ to $-3 \%$ ]) vs the telaprevir regimen. DAA therapy was also associated with decreased risk of fatigue, headache, nausea, anemia, and rash (eTable 10 in the Supplement).

Pooled Adverse Event Rates for DAA Regimens | DAA therapy was frequently associated with experiencing any adverse event (44 trials, $\mathrm{n}=8045 ; 73.3 \%$ [95\% Cl, 68.0\% to $78.1 \%$ ]; $l^{2}=95 \%$ ) (eFigure 4 in the Supplement), though serious adverse events (44 studies, $\mathrm{n}=8070 ; 1.9 \%$ [95\% Cl, $1.5 \%$ to $2.4 \%] ; I^{2}=33 \%$ ) (eFigure 5 in the Supplement) and withdrawal due to adverse events (44 studies, $\mathrm{n}=8060 ; 0.4 \%[95 \% \mathrm{Cl}, 0.3 \%$ to $0.6 \%] ; I^{2}=0 \%$ ) (eFigure 6 in the Supplement) were infrequent (eTable 11 in the Supplement). Pooled 
Figure 3. Direct-Acting Antiviral Regimens and Pooled Sustained Virologic Response Rates in People With Genotype 1 Hepatitis C Virus Infection

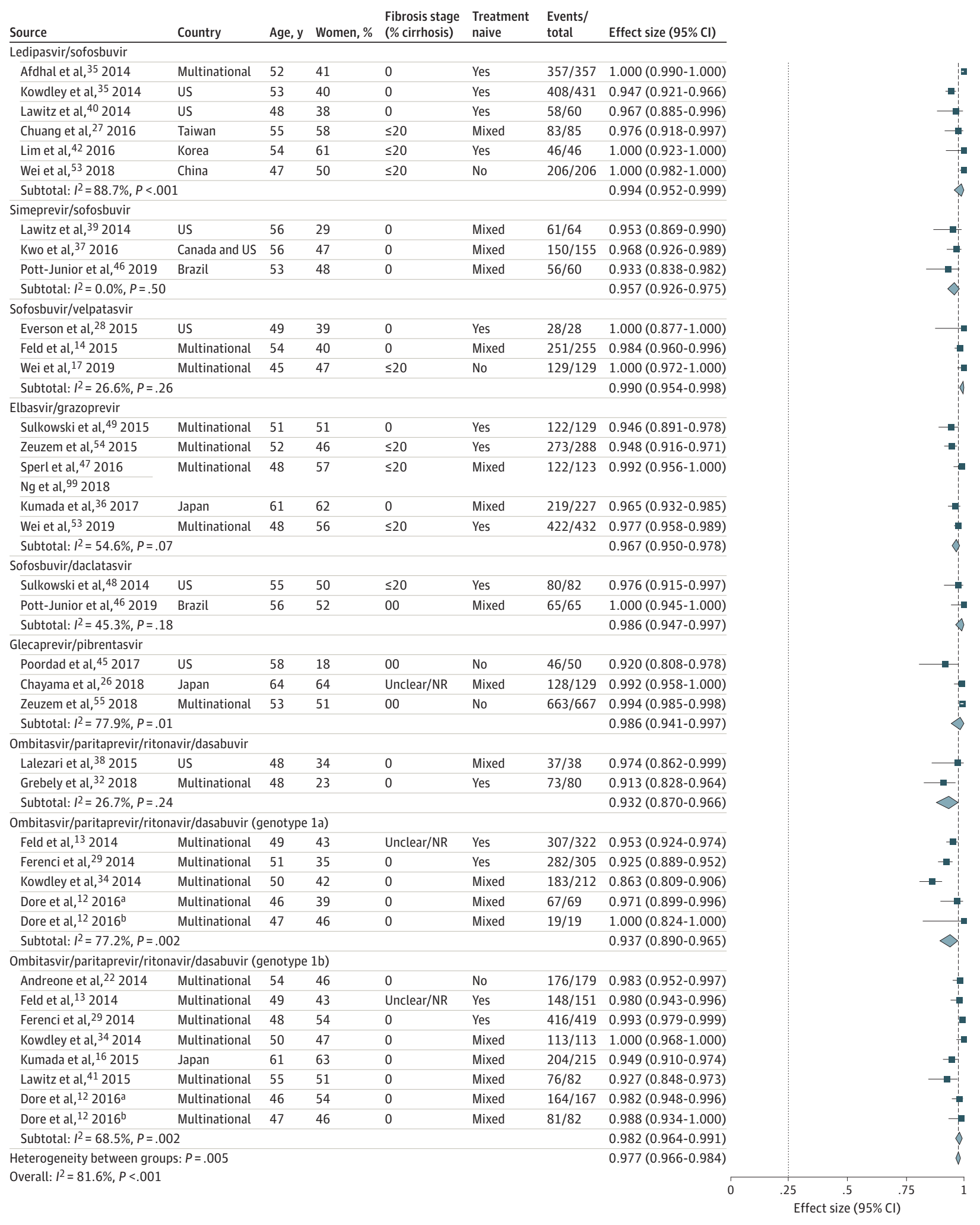

The area of each square represents each pooled estimate (subgroup or overall a Treatment-naive.

analysis), and the width of each diamond represents the confidence interval for b $\quad$ Treatment-experienced.

the pooled estimate. The dashed line indicates the overall measure of effect.

SVR indicates sustained virologic response. 
rates for specific adverse events ranged from $2.4 \%$ (anemia) to $18.7 \%$ (headache) (eTables 12 and 13 in the Supplement). There was some variability by DAA regimen in estimates of adverse events; estimates were generally higher for ombitasvir/paritaprevir/ritonavir/ dasabuvir with ribavirin than without ribavirin (eTables 11-13 in the Supplement). Adverse event estimates were generally similar when studies were stratified according to baseline cirrhosis status and prior antiviral therapy experience.

\section{Adolescents}

Seven treatment studies ( $n=348$ ) of DAA regimens in adolescents reported harms, but methods for reporting and assessing harms were generally not well described (eTable 14 in the Supplement). ${ }^{56-62}$ Rates of any adverse event were $27 \%$ in 1 study ${ }^{62}$ and ranged from $71 \%$ to $87 \%$ in 4 studies. ${ }^{57,59-61}$ There were no withdrawals due to adverse events reported in 5 studies, ${ }^{57,59-62}$ and 1 study ${ }^{61}$ reported 1 serious adverse event (a grade 3 joint injury). Rates of other adverse events were highly variable. For example, $3 \%$ to $48 \%$ of study participants reported headache. Stratification according to DAA regimen did not explain the observed variability.

\section{SVR and Health Outcomes}

Key Question 9. What is the association between experiencing SVR following antiviral treatment and reduction in risk of HCV-related adverse health outcomes?

Thirty cohort studies reported associations between achieving SVR after antiviral treatment vs noSVR and clinical outcomes (eTable 15 in the Supplement). ${ }^{63-66,68-82,84-94}$ Sample sizes ranged from 131 to 50886 (total $n=116659$ ), mean age ranged from 42 to 69 years, and the proportion of women ranged from $1 \%$ to $56 \%$. Seventeen studies were conducted in Japan (including some with overlapping populations), ${ }^{63,64,71,73-75,78-81,84-86,89,90,92,93} 4$ in other Asian countries, ${ }^{82,88,91,94} 7$ in the US (all except for $1^{87}$ conducted in Veterans Affairs populations), ${ }^{65,66,69,70,72,77,87}$ and 2 in Europe. ${ }^{68,76}$ When genotype was reported, genotype 1 was generally the most common (36\%-89\%) and genotype 2 the second most common (6\%-52\%). Mean follow-up ranged from 1.5 to 10 years in all studies except for 1 study that described follow-up of at least 1 year. ${ }^{88}$ Twenty-six studies evaluated interferon-based therapies. Three studies focused on DAAs, ${ }^{66,68,77} 1$ study evaluated interferon-based treatments and DAAs, ${ }^{77}$ and 1 study did not report what type of treatment was administered (likely primarily interferon-based therapies). ${ }^{72}$ All studies were rated fair quality (eTable 16 in the Supplement).

SVR was associated with significantly decreased risk of all-cause mortality (13 studies, $\mathrm{n}=36$ 986; $\mathrm{HR}, 0.40$ [95\% Cl, 0.28 to 0.56]; $r^{2}=52 \%$ ) (Figure 4). ${ }^{63,65,66,68-70,75,76,80,84,87,93,94}$ Studies with longer duration of follow-up ( $>5$ years) reported a stronger association between SVR after antiviral therapy and reduced risk of all-cause mortality (pooled HR, 0.33 [95\% Cl, 0.24 to 0.46]) than those with shorter follow-up (pooled HR, 0.64 [95\% Cl, 0.56 to 0.74]) $(P=.003$ for interaction). SVR was also associated with decreased risk of hepatocellular carcinoma (2O studies, $\mathrm{n}=84$ 491; pooled HR, 0.29 [95\% Cl, 0.23 to 0.38 ]; $P^{2}=19 \%$ ) (Figure 4), ${ }^{63,64,68,70-74,77-79,81,82,84-86,89,90,92,94}$ liver-related mortality (4 studies, $\mathrm{n}=5953$; pooled $\mathrm{HR}, 0.11[95 \% \mathrm{Cl}$, 0.04 to 0.27 ]; $P^{2}=0 \%$ ) (eFigure 7 in the Supplement), ${ }^{63,75,80,93}$ and cirrhosis ( 4 cohorts reported in 3 studies, $n=16735$; pooled HR, 0.36 [95\% Cl, 0.33 to 0.40]; $I^{2}=0 \%$ ) (eFigure 8 in the Supplement). ${ }^{69,72,91}$ There were no statistically significant interactions when studies were stratified according to how well they adjusted for key confounders, duration of follow-up, country/setting, or the proportion of participants with cirrhosis at baseline (eTable 15 in the Supplement). Results were also similar when studies with potentially overlapping populations were excluded.

\section{Discussion}

The findings in this evidence report are summarized in the Table. Since the prior USPSTF recommendation, there has been a major shift in antiviral therapy to all-oral DAA regimens without interferon. New pooled evidence indicates that SVR rates with currently recommended all-oral DAA regimens are substantially higher (>95\%) than with interferon-based therapies evaluated in the prior review (68\%-78\%). ${ }^{9}$ Although statistical heterogeneity was present in pooled estimates of SVR rates, findings were robust when studies were stratified according to the DAA regimen evaluated, study quality, prior treatment status, and cirrhosis status. Few randomized trials directly compared a current DAA regimen vs placebo or an older antiviral regimen, but those available also found DAA therapy associated with greater effectiveness. DAA regimens were associated with fewer harms than older interferon-containing therapies. Evidence on DAA therapies in adolescents was limited, but consistently reported high (97\%-100\%) SVR rates.

Direct evidence on the effects of antiviral therapy on clinical outcomes is limited. Although several randomized trials found interferon therapy associated with decreased risk of hepatocellular carcinoma compared with no antiviral therapy, they did not meet inclusion criteria for this report because they focused on patients with cirrhosis at baseline or used a nonstandard regimen. ${ }^{101-108}$ Studies of DAA therapies were not designed to assess effects on mortality or other long-term clinical outcomes. There were few cohort studies of antiviral therapy vs no therapy, results were somewhat inconsistent, and findings were susceptible to residual confounding. Given the limited direct evidence on the effects of antiviral therapy on clinical outcomes, cohort studies of the association between SVR after antiviral therapy vs no SVR and clinical outcomes may help to understand potential clinical effects of DAA therapy. As in the prior USPSTF review, there was a consistent association between SVR after antiviral therapy and improved clinical outcomes, including mortality and hepatocellular carcinoma. ${ }^{9}$

The findings in this evidence report regarding the benefits and harms of current DAA regimens were consistent with a recent systematic review that also reported high (>95\%) SVR rates in genotype 1 infection without cirrhosis, high SVR rates but more limited evidence for other HCV genotypes, low rates of serious adverse events and treatment discontinuation, and higher adverse event rates with ribavirin. ${ }^{109}$ The results are also consistent with a systematic review that found insufficient evidence from clinical trials to determine effects of DAA regimens on HCV-related mortality and morbidity ${ }^{110}$; unlike that review, this one also evaluated the indirect chain of evidence linking DAA therapy with SVR, and SVR with clinical outcomes. This review is consistent with prior reviews that found a consistent association between an SVR after antiviral therapy and reduced risk of mortality and hepatocellular carcinoma. ${ }^{111-113}$

Research is needed to better understand the association between use of current DAA therapy and clinical outcomes. Long-term 


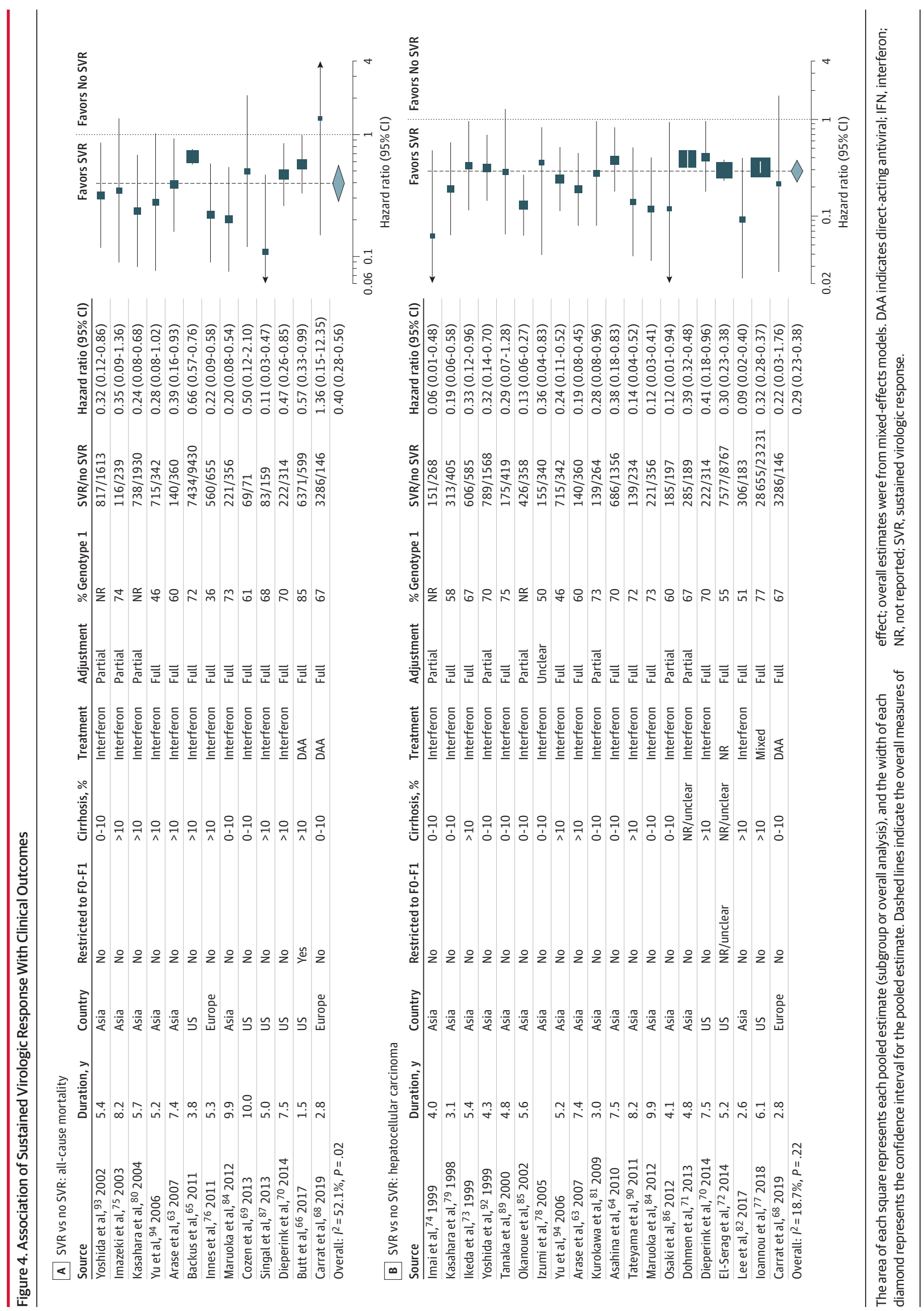




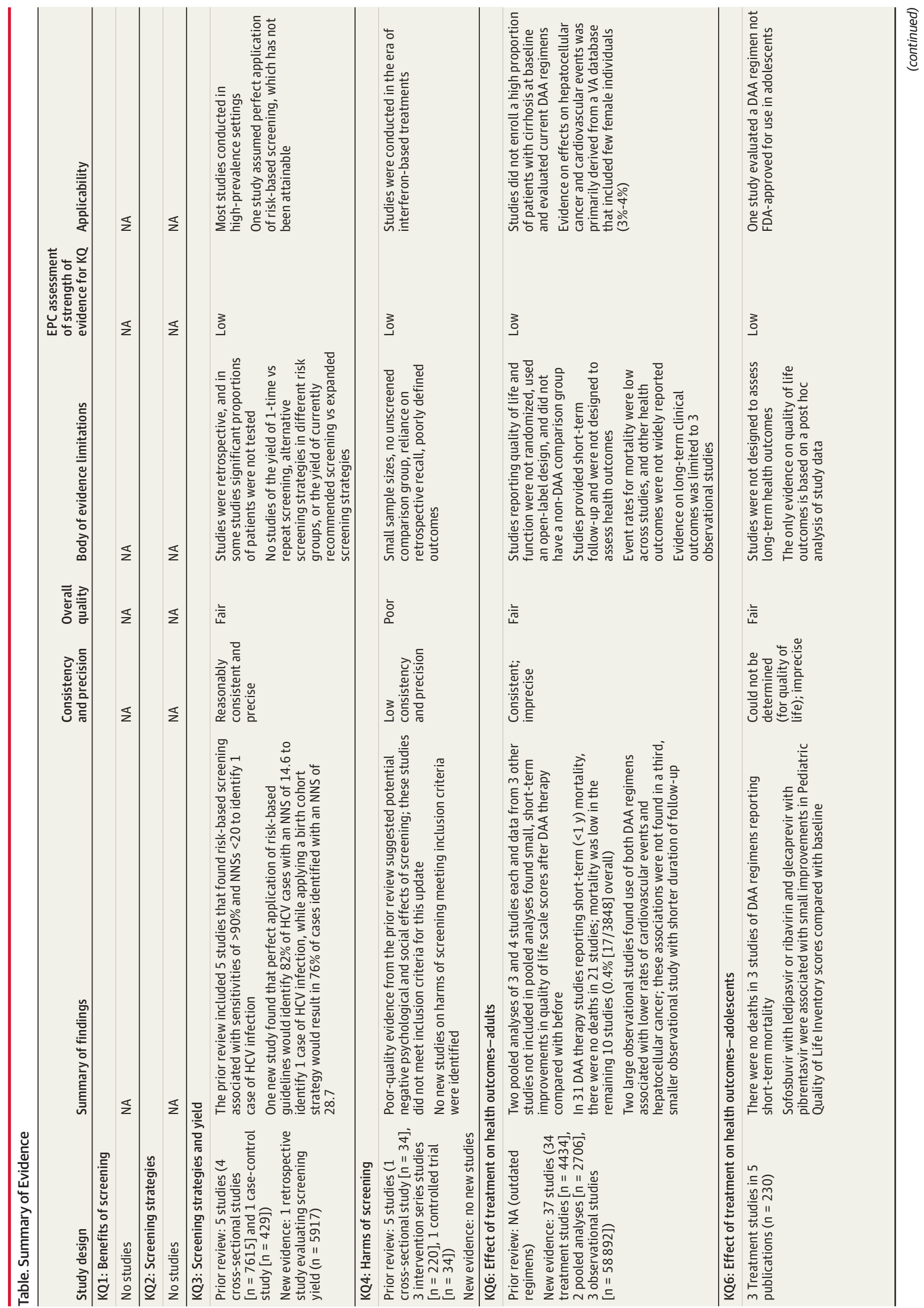




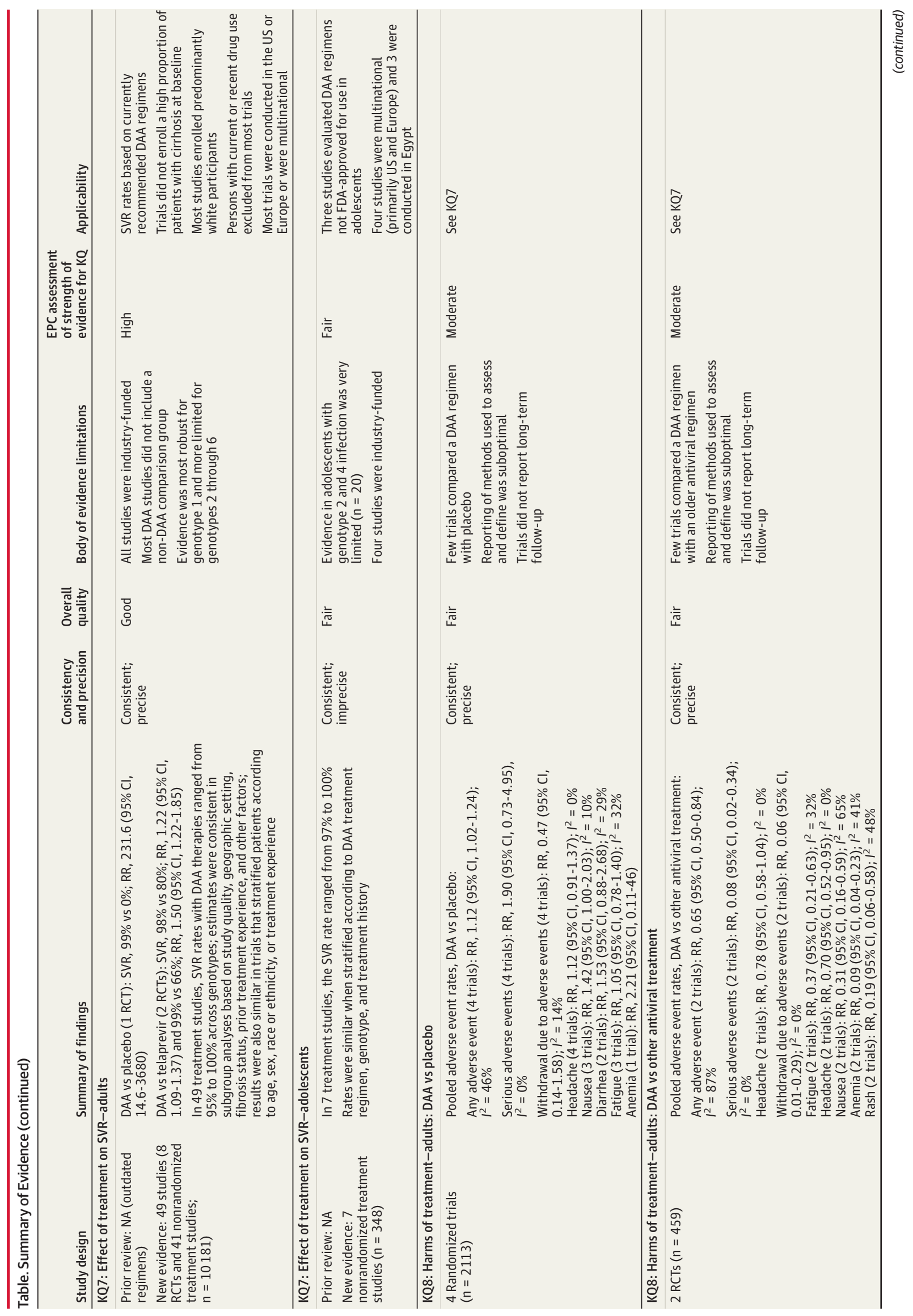




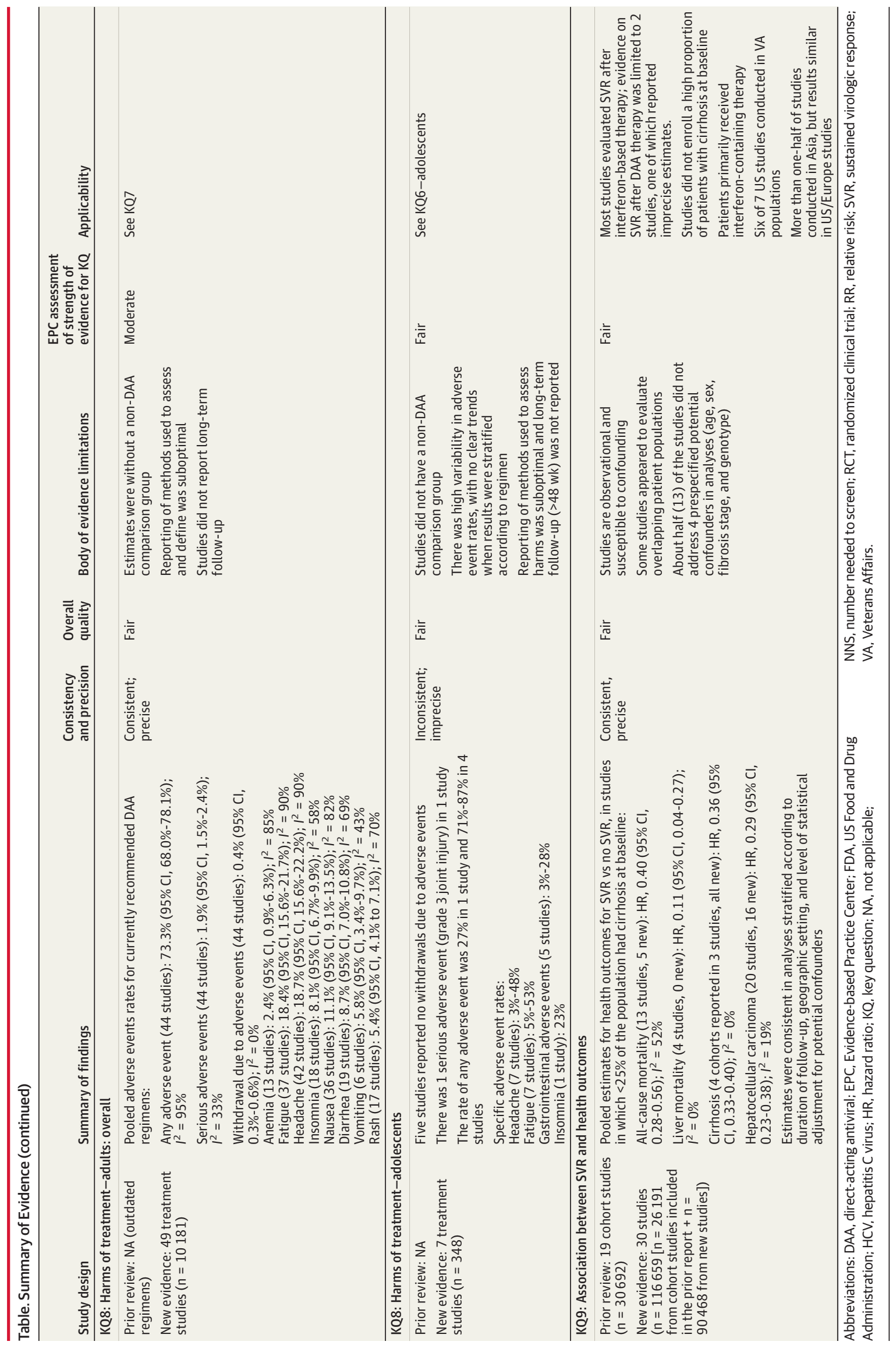


randomized trials of treatment vs no treatment would be ethically challenging and difficult to carry out. Alternatively, large cohort studies that measure important confounders could be highly informative. Trials and cohort studies that measure effects on quality of life, function, and extrahepatic effects of HCV infection would also be helpful for understanding effects of DAA regimens on these shorterterm clinical outcomes. Studies on the association between SVR after DAA therapy and clinical outcomes would help to verify the link between SVR and clinical outcomes with current DAA therapies. Additional studies would be helpful for confirming the effectiveness of DAA regimens in adolescents, including long-term outcomes. ${ }^{114}$ Well-designed prospective studies are needed to understand the effects of different HCV screening strategies, including repeat screening, on diagnostic yield.

\section{Limitations}

This review has several limitations. First, because there were few randomized trials of current DAA regimens, nonrandomized treatment studies were included, among which were studies without a non-DAA therapy comparison group. Causality cannot be concluded from such studies. Nonetheless, such studies were considered highly informative for SVR, an objective measure with rates without treatment close to zero. However, more subjective outcomes such as quality of life, function, and adverse events are more difficult to interpret in the absence of randomization or a comparison group. Second, no study of DAA therapy was conducted in screen-detected patients, and few studies reported presence or severity of baseline symptoms. Therefore, to evaluate effectiveness of DAA therapies in populations likely to be identified by screening, this report selected studies based on proxy factors, specifically a low prevalence of cirrhosis and prior DAA experience. Research studies of DAA therapy could overestimate SVR rates compared with typical clinical practice. However, observational studies reported SVR rates of $90 \%$, only modestly lower than observed in the trials. ${ }^{115,116}$

Third, some studies of DAA therapy in adolescents evaluated regimens approved for adults but not children. Fourth, evidence on potential long-term harms of DAA therapy exposure was limited. However, limited evidence indicates no increased risk of hepatocellular carcinoma with DAA therapy compared with interferonbased therapy through around 3 years of follow-up. ${ }^{68}$

Fifth, non-English-language articles were excluded. Sixth, formal assessment for small sample effects (a potential marker of publication bias) using graphical or statistical methods was not performed because of the small number of randomized trials.

\section{Conclusions}

Direct evidence on the effects of HCV screening on clinical outcomes remains unavailable, but all-oral DAA regimens were associated with SVR rates greater than $95 \%$ and few short-term harms relative to older antiviral therapies. An SVR after antiviral therapy was associated with improved clinical outcomes compared with no SVR.

\section{ARTICLE INFORMATION}

Accepted for Publication: December 3, 2019.

Published Online: March 2, 2020.

doi:10.1001/jama.2019.20788

Correction: This article was corrected online on March 10, 2020, for incorrect data in the abstract Conclusions, incorrect presentation in Figure 1, and incorrect data in Figure 3.

Author Contributions: Dr Chou had full access to all of the data in the study and takes responsibility for the integrity of the data and the accuracy of the data analysis.

Concept and design: Chou, Wagner, Jou.

Acquisition, analysis, or interpretation of data: All authors.

Drafting of the manuscript: Chou, Dana, Fu, Wagner Ramirez, Grusing.

Critical revision of the manuscript for important intellectual content: Chou, Zakher, Jou.

Statistical analysis: Chou, Dana, Fu.

Obtained funding: Chou.

Administrative, technical, or material support: Dana, Wagner, Grusing

Supervision: Chou, Wagner, Jou.

Conflict of Interest Disclosures: Dr Chou reported receiving personal fees from the World Health Organization. Dr Fu reported receiving grants from Oregon Health \& Science University. No other disclosures were reported.

Funding/Support: This research was funded under contract HHSA290201500009i, Task Order 7, from the Agency for Healthcare Research and Quality (AHRQ), US Department of Health and Human Services, under a contract to support the US Preventive Services Task Force (USPSTF).
Role of the Funder/Sponsor: Investigators worked with USPSTF members and AHRQ staff to develop the scope, analytic framework, and key questions for this review. AHRQ had no role in study selection, quality assessment, or synthesis. AHRQ staff provided project oversight, reviewed the report to ensure that the analysis met methodological standards, and distributed the draft for peer review. Otherwise, AHRQ had no role in the conduct of the study; collection, management, analysis, and interpretation of the data; and preparation, review, or approval of the manuscript findings. The opinions expressed in this document are those of the authors and do not reflect the official position of AHRQ or the US Department of Health and Human Services.

Additional Contributions: We thank the AHRQ Medical Officer (Iris Mabry-Hernandez, MD). We also acknowledge past and current USPSTF members who contributed to topic deliberations. The USPSTF members, external reviewers, and federal partner reviewers did not receive financial compensation for their contributions.

Additional Information: A draft version of this evidence report underwent external peer review from 6 content experts (Michael F. Chang, MD, Oregon Health \& Science University; Oluwaseun Falade-Nwulia, MBBS, Johns Hopkins University; Yngve Falck-Ytter, MD, Louis Stokes VA Cleveland Medical Center; Brenna L. Hughes, MD, Duke University; Karla Thornton, MD, University of New Mexico; and John W. Ward, MD, Task Force for Global Health Inc) and 3 federal partners representing the Centers for Disease Control and Prevention and 1 federal partner representing the National Institutes of Health, National Institute of
Allergy and Infectious Diseases. None of the reviewers received compensation for their role in reviewing the report. Comments from reviewers were presented to the USPSTF during its deliberation of the evidence and were considered in preparing the final evidence review.

Editorial Disclaimer: This evidence report is presented as a document in support of the accompanying USPSTF Recommendation Statement. It did not undergo additional peer review after submission to JAMA

\section{REFERENCES}

1. Hofmeister MG, Rosenthal EM, Barker LK, et al. Estimating prevalence of hepatitis C virus infection in the United States, 2013-2016. Hepatology. 2019; 69(3):1020-1031. doi:10.1002/hep.30297

2. Centers for Disease Control and Prevention (CDC). Surveillance for viral hepatitis-United States, 2016. Updated October 1, 2018. Accessed June 25, 2019. https://www.cdc.gov/hepatitis/ statistics/2016surveillance/commentary.htm

3. Squires JE, Balistreri WF. Hepatitis C virus infection in children and adolescents. Hepatol Commun. 2017;1(2):87-98. doi:10.1002/hep4.1028

4. Moyer VA; U.S. Preventive Services Task Force. Screening for hepatitis $\mathrm{C}$ virus infection in adults: U.S. Preventive Services Task Force recommendation statement. Ann Intern Med. 2013 159(5):349-357. doi:10.7326/0003-4819-159-5 201309030-00672

5. Chou R, Cottrell EB, Wasson N, Rahman B, Guise $J M$. Screening for hepatitis $C$ virus infection in adults: a systematic review for the U.S. Preventive Services Task Force. Ann Intern Med. 2013;158(2): 
101-108. doi:10.7326/0003-4819-158-2-20130115000574

6. Chou R, Cottrell E, Wasson N, Rahman B, Guise J-M. Screening for Hepatitis C Virus Infection in Adults: Comparative Effectiveness Review No. 69. Agency for Healthcare Research and Quality; 2012. AHRQ publication 12(13)-EHCO9O-EF.

7. Chou R, Hartung D, Rahman B, Wasson N, Cottrell E, Fu R. Treatment for Hepatitis C Virus Infection in Adults. Agency for Healthcare Research and Quality; 2012.

8. Chou R, Hartung D, Rahman B, Wasson N, Cottrell EB, Fu R. Comparative effectiveness of antiviral treatment for hepatitis $C$ virus infection in adults: a systematic review. Ann Intern Med. 2013; 158(2):114-123. doi:10.7326/0003-4819-158-2201301150-00576

9. Chou R, Hartung D, Rahman B, Wasson N, Cottrell E, Fu R. Treatment for Hepatitis C Virus Infection in Adults: Comparative Effectiveness Review No. 76. Agency for Healthcare Research and Quality; 2012. AHRQ publication 12(13)-EHC113-EF.

10. American Association for the Study of Liver Diseases, Infectious Diseases Society of America. HCV guidance: recommendations for testing, managing, and treating hepatitis C: overview of cost, reimbursement, and cost-effectiveness considerations for hepatitis $\mathrm{C}$ treatment regimens. Updated September 21, 2017. Accessed June 25 , 2019. https://www.hcvguidelines.org/evaluate/cost 11. Higgins JP, Thompson SG. Quantifying heterogeneity in a meta-analysis. Stat Med. 2002; 21(11):1539-1558. doi:10.1002/sim.1186

12. Dore GJ, Conway B, Luo Y, et al. Efficacy and safety of ombitasvir/paritaprevir/r and dasabuvir compared to IFN-containing regimens in genotype 1 HCV patients: the MALACHITE-I/II trials. J Hepatol. 2016;64(1):19-28. doi:10.1016/j.jhep.2015.08.015

13. Feld JJ, Kowdley KV, Coakley E, et al. Treatment of HCV with ABT-450/r-ombitasvir and dasabuvir with ribavirin. N Engl J Med. 2014;370(17):1594-1603. doi:10.1056/NEJMoa1315722

14. Feld JJ, Jacobson IM, Hézode C, et al; ASTRAL-1 Investigators. Sofosbuvir and velpatasvir for HCV genotype 1, 2, 4, 5, and 6 infection. N Engl J Med. 2015;373(27):2599-2607. doi:10.1056/ NEJMoa1512610

15. Foster GR, Afdhal N, Roberts SK, et al; ASTRAL-2 Investigators; ASTRAL-3 Investigators. Sofosbuvir and velpatasvir for HCV genotype 2 and 3 infection. N Engl J Med. 2015;373(27):2608-2617. doi:10.1056/NEJMoa1512612

16. Kumada H, Chayama K, Rodrigues L Jr, et al. Randomized phase 3 trial of ombitasvir/ paritaprevir/ritonavir for hepatitis C virus genotype 1b-infected Japanese patients with or without cirrhosis. Hepatology. 2015;62(4):1037-1046. doi: 10.1002/hep.27972

17. Wei L, Jia JD, Wang FS, et al; C-CORAL Investigators. Efficacy and safety of elbasvir/grazoprevir in participants with hepatitis C virus genotype 1, 4, or 6 infection from the Asia-Pacific region and Russia: final results from the randomized C-CORAL study. J Gastroenterol Hepatol. 2019;34(1):12-21.

18. Abergel A, Metivier S, Samuel D, et al. Ledipasvir plus sofosbuvir for 12 weeks in patients with hepatitis $C$ genotype 4 infection. Hepatology. 2016;64(4):1049-1056. doi:10.1002/hep.28706
19. Abergel A, Asselah T, Metivier $S$, et al. Ledipasvir-sofosbuvir in patients with hepatitis C virus genotype 5 infection: an open-label, multicentre, single-arm, phase 2 study. Lancet Infect Dis. 2016;16(4):459-464. doi:10.1016/S14733099(15)00529-0

20. Afdhal N, Zeuzem S, Kwo P, et al; ION-1 Investigators. Ledipasvir and sofosbuvir for untreated HCV genotype 1 infection. N Engl J Med. 2014;370(20):1889-1898. doi:10.1056/ NEJMoa1402454

21. Ahmed OA, Kaisar HH, Badawi R, et al. Efficacy and safety of sofosbuvir-ledipasvir for treatment of a cohort of Egyptian patients with chronic hepatitis C genotype 4 infection. Infect Drug Resist. 2018;11: 295-298. doi:10.2147/IDR.S153060

22. Andreone P, Colombo MG, Enejosa JV, et al. ABT-450, ritonavir, ombitasvir, and dasabuvir achieves $97 \%$ and $100 \%$ sustained virologic response with or without ribavirin in treatment-experienced patients with HCV genotype 1b infection. Gastroenterology. 2014;147 (2):359-365. doi:10.1053/j.gastro.2014.04.045

23. Asselah T, Kowdley KV, Zadeikis N, et al. Efficacy of glecaprevir/pibrentasvir for 8 or 12 weeks in patients with hepatitis $C$ virus genotype 2 , 4,5 , or 6 infection without cirrhosis. Clin Gastroenterol Hepatol. 2018;16(3):417-426. doi:10. 1016/j.cgh.2017.09.027

24. Asselah T, Lee SS, Yao BB, et al. Efficacy and safety of glecaprevir/pibrentasvir in patients with chronic hepatitis $C$ virus genotype 5 or 6 infection (ENDURANCE-5,6): an open-label, multicentre, phase 3b trial. Lancet Gastroenterol Hepatol. 2019;4 (1):45-51. doi:10.1016/S2468-1253(18)30341-8

25. Brown A, Hézode C, Zuckerman E, et al; C-SCAPE Study Investigators. Efficacy and safety of 12 weeks of elbasvir \pm grazoprevir \pm ribavirin in participants with hepatitis $C$ virus genotype 2, 4, 5 or 6 infection: the C-SCAPE study. J Viral Hepat. 2018;25(5):457-464. doi:10.1111/jvh.12801

26. Chayama K, Suzuki F, Karino Y, et al. Efficacy and safety of glecaprevir/pibrentasvir in Japanese patients with chronic genotype 1 hepatitis $C$ virus infection with and without cirrhosis. J Gastroenterol. 2018;53(4):557-565. doi:10.1007/s00535-017-13915

27. Chuang WL, Chien RN, Peng CY, et al. Ledipasvir/sofosbuvir fixed-dose combination tablet in Taiwanese patients with chronic genotype 1 hepatitis C virus. J Gastroenterol Hepatol. 2016;31 (7):1323-1329. doi:10.1111/jgh.13305

28. Everson GT, Towner WJ, Davis MN, et al. Sofosbuvir with velpatasvir in treatment-naive noncirrhotic patients with genotype 1 to 6 hepatitis $C$ virus infection: a randomized trial. Ann Intern Med. 2015;163(11):818-826. doi:10.7326/M15-1000

29. Ferenci P, Bernstein D, Lalezari J, et al; PEARL-III Study; PEARL-IV Study. ABT-450/r-ombitasvir and dasabuvir with or without ribavirin for HCV. N Engl J Med. 2014;370 (21):1983-1992. doi:10.1056/NEJMoa1402338

30. Gane EJ, Hyland RH, An D, et al. Efficacy of ledipasvir and sofosbuvir, with or without ribavirin, for 12 weeks in patients with HCV genotype 3 or 6 infection. Gastroenterology. 2015;149(6):1454-1461. doi:10.1053/j.gastro.2015.07.063

31. Grebely J, Dalgard O, Conway B, et al; SIMPLIFY Study Group. Sofosbuvir and velpatasvir for hepatitis $C$ virus infection in people with recent injection drug use (SIMPLIFY): an open-label, single-arm, phase 4, multicentre trial. Lancet Gastroenterol Hepatol. 2018;3(3):153-161. doi:10.1016/S2468-1253(17)30404-1

32. Grebely J, Conway B, Cunningham EB, et al; D3FEAT Study Group. Paritaprevir, ritonavir, ombitasvir, and dasabuvir with and without ribavirin in people with HCV genotype 1 and recent injecting drug use or receiving opioid substitution therapy. Int J Drug Policy. 2018;62:94-103. doi:10 1016/j.drugpo.2018.10.004

33. Hézode C, Asselah T, Reddy KR, et al. Ombitasvir plus paritaprevir plus ritonavir with or without ribavirin in treatment-naive and treatment-experienced patients with genotype 4 chronic hepatitis $C$ virus infection (PEARL-I): a randomised, open-label trial. Lancet. 2015;385 (9986):2502-2509. doi:10.1016/S0140-6736(15) 60159-3

34. Kowdley KV, Gordon SC, Reddy KR, et al; ION-3 Investigators. Ledipasvir and sofosbuvir for 8 or 12 weeks for chronic HCV without cirrhosis. N Engl J Med. 2014;370(20):1879-1888. doi:10.1056/ NEJMoa1402355

35. Kowdley KV, Lawitz E, Poordad F, et al. Phase $2 b$ trial of interferon-free therapy for hepatitis C virus genotype 1. N Engl J Med. 2014;370(3):222-232. doi:10.1056/NEJMoa1306227

36. Kumada H, Suzuki Y, Karino Y, et al. The combination of elbasvir and grazoprevir for the treatment of chronic HCV infection in Japanese patients: a randomized phase II/III study. J Gastroenterol. 2017;52(4):520-533. doi:10.1007/ s00535-016-1285-y

37. Kwo P, Gitlin N, Nahass R, et al. Simeprevir plus sofosbuvir (12 and 8 weeks) in hepatitis $C$ virus genotype 1-infected patients without cirrhosis: OPTIMIST-1, a phase 3, randomized study. Hepatology. 2016;64(2):370-380. doi:10.1002/hep.28467

38. Lalezari J, Sullivan JG, Varunok P, et al. Ombitasvir/paritaprevir/r and dasabuvir plus ribavirin in HCV genotype 1-infected patients on methadone or buprenorphine. J Hepatol. 2015;63 (2):364-369. doi:10.1016/j.jhep.2015.03.029

39. Lawitz E, Sulkowski MS, Ghalib R, et al. Simeprevir plus sofosbuvir, with or without ribavirin, to treat chronic infection with hepatitis C virus genotype 1 in non-responders to pegylated interferon and ribavirin and treatment-naive patients: the COSMOS randomised study. Lancet. 2014:384(9956):1756-1765. doi:10.1016/SO140-6736 (14)61036-9

40. Lawitz E, Poordad FF, Pang PS, et al. Sofosbuvir and ledipasvir fixed-dose combination with and without ribavirin in treatment-naive and previously treated patients with genotype 1 hepatitis C virus infection (LONESTAR): an open-label, randomised, phase 2 trial. Lancet. 2014; 383(9916):515-523. doi:10.1016/S0140-6736(13) 62121-2

41. Lawitz E, Makara M, Akarca US, et al. Efficacy and safety of ombitasvir, paritaprevir, and ritonavir in an open-label study of patients with genotype $1 \mathrm{~b}$ chronic hepatitis $C$ virus infection with and without cirrhosis. Gastroenterology. 2015;149(4):971-80. doi:10.1053/j.gastro.2015.07.001

42. Lim YS, Ahn SH, Lee KS, et al. A phase Illb study of ledipasvir/sofosbuvir fixed-dose combination tablet in treatment-naïve and treatment- 
experienced Korean patients chronically infected with genotype 1 hepatitis C virus. Hepatol Int. 2016; 10(6):947-955. doi:10.1007/s12072-016-9726-5

43. Nelson DR, Cooper JN, Lalezari JP, et al; ALLY-3 Study Team. All-oral 12-week treatment with daclatasvir plus sofosbuvir in patients with hepatitis C virus genotype 3 infection: ALLY-3 phase III study. Hepatology. 2015;61(4):1127-1135. doi:10.1002/hep. 27726

44. Pianko S, Flamm SL, Shiffman ML, et al. Sofosbuvir plus velpatasvir combination therapy fo treatment-experienced patients with genotype 1 or 3 hepatitis $C$ virus infection: a randomized trial. Ann Intern Med. 2015;163(11):809-817. doi:10.7326/M151014

45. Poordad F, Felizarta F, Asatryan A, et al. Glecaprevir and pibrentasvir for 12 weeks for hepatitis $C$ virus genotype 1 infection and prior direct-acting antiviral treatment. Hepatology. 2017; 66(2):389-397. doi:10.1002/hep.29081

46. Pott-Junior H, Bricks G, Grandi G, Figueiredo Senise J, Castelo Filho A. Sofosbuvir in combination with daclatasvir or simeprevir for 12 weeks in noncirrhotic subjects chronically infected with hepatitis $C$ virus genotype 1 : a randomized clinical trial. Clin Microbiol Infect. 2019;25(3):365-371. doi: 10.1016/j.cmi.2018.06.007

47. Sperl J, Horvath G, Halota W, et al. Efficacy and safety of elbasvir/grazoprevir and sofosbuvir/pegylated interferon/ribavirin: a phase III randomized controlled trial. J Hepatol. 2016;65 (6):1112-1119. doi:10.1016/j.jhep.2016.07.050

48. Sulkowski MS, Gardiner DF, Rodriguez-Torres M, et al; Al444040 Study Group. Daclatasvir plus sofosbuvir for previously treated or untreated chronic HCV infection. N Engl J Med. 2014;370(3): 211-221. doi:10.1056/NEJMoa1306218

49. Sulkowski M, Hezode C, Gerstoft J, et al. Efficacy and safety of 8 weeks versus 12 weeks of treatment with grazoprevir (MK-5172) and elbasvir (MK-8742) with or without ribavirin in patients with hepatitis $C$ virus genotype 1 mono-infection and HIV/hepatitis C virus co-infection (C-WORTHY) a randomised, open-label phase 2 trial. Lancet. 2015;385(9973):1087-1097. doi:10.1016/S0140-6736 (14)61793-1

50. Toyoda H, Chayama K, Suzuki F, et al. Efficacy and safety of glecaprevir/pibrentasvir in Japanese patients with chronic genotype 2 hepatitis $C$ virus infection. Hepatology. 2018;67(2):505-513. doi:10. 1002/hep.29510

51. Waked I, Shiha G, Qaqish RB, et al. Ombitasvir paritaprevir, and ritonavir plus ribavirin for chronic hepatitis $C$ virus genotype 4 infection in Egyptian patients with or without compensated cirrhosis (AGATE-II): a multicentre, phase 3, partly randomised open-label trial. Lancet Gastroenterol Hepatol. 2016;1(1):36-44. doi:10.1016/S2468-1253(16) 30002-4

52. Wei L, Xie Q, Hou JL, et al. Ledipasvir/ sofosbuvir for treatment-naive and treatment-experienced Chinese patients with genotype $1 \mathrm{HCV}$ : an open-label, phase $3 \mathrm{~b}$ study. Hepatol Int. 2018;12(2):126-132. doi:10.1007/ s12072-018-9856-z

53. Wei L, Lim SG, Xie Q, et al. Sofosbuvirvelpatasvir for treatment of chronic hepatitis $C$ virus infection in Asia: a single-arm, open-label, phase 3 trial. Lancet Gastroenterol Hepatol. 2019;4 (2):127-134. doi:10.1016/S2468-1253(18)30343-1
54. Zeuzem S, Ghalib R, Reddy KR, et al. Grazoprevir-elbasvir combination therapy for treatment-naive cirrhotic and noncirrhotic patients with chronic hepatitis $C$ virus genotype 1,4 , or 6 infection: a randomized trial. Ann Intern Med. 2015; 163(1):1-13. doi:10.7326/M15-0785

55. Zeuzem S, Foster GR, Wang S, et al. Glecaprevir-pibrentasvir for 8 or 12 weeks in HCV genotype 1 or 3 infection. N Engl J Med. 2018;378 (4):354-369. doi:10.1056/NEJMoa1702417

56. Abdel Ghaffar TY, El Naghi S, Abdel Gawad M, et al. Safety and efficacy of combined sofosbuvir/daclatasvir treatment of children and adolescents with chronic hepatitis $C$ genotype 4 . J Viral Hepat. 2019;26(2):263-270. doi:10.1111/jvh. 13032

57. Balistreri WF, Murray KF, Rosenthal $P$, et al. The safety and effectiveness of ledipasvir-sofosbuvir in adolescents $12-17$ years old with hepatitis $C$ virus genotype 1 infection. Hepatology. 2017;66(2):371378. doi:10.1002/hep.28995

58. El-Karaksy H, Mogahed EA, Abdullatif $\mathrm{H}$, et al. Sustained viral response in genotype 4 chronic hepatitis $C$ virus-infected children and adolescents treated with sofosbuvir/ledipasvir. J Pediatr Gastroenterol Nutr. 2018;67(5):626-630. doi:10. 1097/MPG.000000000000210

59. Jonas MM, Squires RH, Rhee SM, et al. Pharmacokinetics, safety, and efficacy of glecaprevir/pibrentasvir in adolescents with chronic HCV: part 1 of the DORA study. Hepatology. 2020 71(2):456-462. doi:10.1002/hep.30840

60. Leung DH, Wirth S, Yao BB, et al. Ombitasvir/paritaprevir/ritonavir with or without dasabuvir and with or without ribavirin for adolescents with HCV genotype 1 or 4. Hepatol Commun. 2018;2(11):1311-1319. doi:10.1002/hep4.1250

61. Wirth S, Rosenthal P, Gonzalez-Peralta RP, et al. Sofosbuvir and ribavirin in adolescents $12-17$ years old with hepatitis $C$ virus genotype 2 or 3 infection. Hepatology. 2017;66(4):1102-1110. doi:10.1002/hep. 29278

62. Yakoot M, El-Shabrawi MH, AbdElgawad MM, et al. Dual sofosbuvir/daclatasvir therapy in adolescent patients with chronic hepatitis $C$ infection. J Pediatr Gastroenterol Nutr. 2018;67(1): 86-89. doi:10.1097/MPG.0000000000001968

63. Arase $Y$, Ikeda K, Suzuki F, et al. Long-term outcome after interferon therapy in elderly patients with chronic hepatitis C. Intervirology. 2007:50(1): 16-23. doi:10.1159/000096308

64. Asahina Y, Tsuchiya K, Tamaki N, et al. Effect of aging on risk for hepatocellular carcinoma in chronic hepatitis C virus infection. Hepatology. 2010;52(2): 518-527. doi:10.1002/hep.23691

65. Backus LI, Boothroyd DB, Phillips BR, Belperio P, Halloran J, Mole LA. A sustained virologic response reduces risk of all-cause mortality in patients with hepatitis C. Clin Gastroenterol Hepatol. 2011;9(6):509-516. doi:10.1016/j.cgh.2011.03.004

66. Butt $A A$, Yan $P$, Simon $T G$, Abou-Samra AB. Effect of paritaprevir/ritonavir/ombitasvir/ dasabuvir and ledipasvir/sofosbuvir regimens on survival compared with untreated hepatitis $C$ virus-infected persons: results from ERCHIVES. Clin Infect Dis. 2017;65(6):1006-1011. doi:10.1093/cid/ cix364

67. Butt AA, Yan P, Shuaib A, Abou-Samra AB Shaikh OS, Freiberg MS. Direct-acting antiviral therapy for HCV infection is associated with a reduced risk of cardiovascular disease events Gastroenterology. 2019;156(4):987-996. doi:10.1053/ j.gastro.2018.11.022

68. Carrat $F$, Fontaine $H$, Dorival $C$, et al; French ANRS CO22 Hepather Cohort. Clinical outcomes in patients with chronic hepatitis $\mathrm{C}$ after direct-acting antiviral treatment: a prospective cohort study. Lancet. 2019;393(10179):1453-1464. doi:10.1016/ S0140-6736(18)32111-1

69. Cozen ML, Ryan JC, Shen H, et al. Nonresponse to interferon-a based treatment for chronic hepatitis C infection is associated with increased hazard of cirrhosis. PLoS One. 2013;8(4):e61568. doi:10.1371/journal.pone.0061568

70. Dieperink E, Pocha C, Thuras P, Knott A, Colton S, Ho SB. All-cause mortality and liver-related outcomes following successful antiviral treatment for chronic hepatitis C. Dig Dis Sci. 2014;59(4):872 880. doi:10.1007/s10620-014-3050-5

71. Dohmen K, Kawano A, Takahashi K, et al. The incidence and risk factors for the development of hepatocellular carcinoma after peginterferon plus ribavirin therapy for chronic hepatitis C. Hepatogastroenterology. 2013;60(128):2034-2038.

72. El-Serag HB, Kramer J, Duan Z, Kanwal F. Racial differences in the progression to cirrhosis and hepatocellular carcinoma in HCV-infected veterans. Am J Gastroenterol. 2014;109(9):1427-1435. doi:10. 1038/ajg.2014.214

73. Ikeda K, Saitoh S, Arase Y, et al. Effect of interferon therapy on hepatocellular carcinogenesis in patients with chronic hepatitis type $\mathrm{C}$ : a long-term observation study of 1,643 patients using statistical bias correction with proportional hazard analysis. Hepatology. 1999;29(4):1124-1130. doi:10.1002/hep.510290439

74. Imai Y, Kawata S, Tamura S, et al; Osaka Hepatocellular Carcinoma Prevention Study Group. Relation of interferon therapy and hepatocellular carcinoma in patients with chronic hepatitis C. Ann Intern Med. 1998;129(2):94-99. doi:10.7326/0003 4819-129-2-199807150-00005

75. Imazeki F, Yokosuka O, Fukai K, Saisho H. Favorable prognosis of chronic hepatitis $\mathrm{C}$ after interferon therapy by long-term cohort study. Hepatology. 2003;38(2):493-502. doi:10.1053/jhep. 2003.50329

76. Innes HA, Hutchinson SJ, Allen $\mathrm{S}$, et al Hepatitis C Clinical Database Monitoring Committee. Excess liver-related morbidity of chronic hepatitis $\mathrm{C}$ patients, who achieve a sustained viral response, and are discharged from care. Hepatology. 2011;54(5):1547-1558. doi:10. 1002/hep.24561

77. Ioannou GN, Green PK, Berry K. HCV eradication induced by direct-acting antiviral agents reduces the risk of hepatocellular carcinoma. J Hepatol. 2018;68(1):25-32. doi:10.1016/j.jhep.2017. 08.030

78. Izumi N, Yasuhiro A, Kurosaki M, et al. Development of hepatocellular carcinoma afte interferon therapy in chronic hepatitis C: is it possible to reduce the incidence by ribanirin and IFN combination therapy? Intervirology. 2005;48 (1):59-63. doi:10.1159/000082096

79. Kasahara A, Hayashi N, Mochizuki K, et al: Osaka Liver Disease Study Group. Risk factors for hepatocellular carcinoma and its incidence after 
interferon treatment in patients with chronic hepatitis C. Hepatology. 1998;27(5):1394-1402. doi: 10.1002/hep.510270529

80. Kasahara A, Tanaka H, Okanoue T, et al. Interferon treatment improves survival in chronic hepatitis $C$ patients showing biochemical as well as virological responses by preventing liver-related death. J Viral Hepat. 2004;11(2):148-156. doi:10. 1046/j.1365-2893.2003.00481.x

81. Kurokawa M, Hiramatsu N, Oze T, et al. Effect of interferon alpha-2b plus ribavirin therapy on incidence of hepatocellular carcinoma in patients with chronic hepatitis. Hepatol Res. 2009;39(5): 432-438. doi:10.1111/j.1872-034X.2008.00477.x

82. Lee SH, Jin YJ, Shin JY, Lee JW. Assessment of hepatocellular carcinoma risk based on peg-interferon plus ribavirin treatment experience in this new era of highly effective oral antiviral drugs. Medicine (Baltimore). 2017;96(1):e5321. doi: 10.1097/MD.0000000000005321

83. Li DK, Ren Y, Fierer DS, et al. The short-term incidence of hepatocellular carcinoma is not increased after hepatitis $C$ treatment with direct-acting antivirals: an ERCHIVES study. Hepatology. 2018;67(6):2244-2253. doi:10.1002/hep. 29707

84. Maruoka D, Imazeki F, Arai M, Kanda T, Fujiwara $\mathrm{K}$, Yokosuka O. Long-term cohort study of chronic hepatitis $\mathrm{C}$ according to interferon efficacy. J Gastroenterol Hepatol. 2012;27(2):291-299. doi: 10.1111/j.1440-1746.2011.06871.x

85. Okanoue T, Itoh Y, Kirishima T, et al. Transient biochemical response in interferon therapy decreases the development of hepatocellular carcinoma for five years and improves the long-term survival of chronic hepatitis $C$ patients. Hepatol Res. 2002;23(1):62-77. doi:10.1016/S13866346(02)00016-5

86. Osaki $Y$, Ueda $Y$, Marusawa $H$, et al. Decrease in alpha-fetoprotein levels predicts reduced incidence of hepatocellular carcinoma in patients with hepatitis $C$ virus infection receiving interferon therapy: a single center study. J Gastroenterol. 2012;47(4):444-451. doi:10.1007/s00535-011-05058

87. Singal AG, Dharia TD, Malet PF, Alqahtani $S$, Zhang S, Cuthbert JA. Long-term benefit of hepatitis $C$ therapy in a safety net hospital system: a cross-sectional study with median 5-year follow-up. BMJ Open. 2013;3(9):e003231. doi:10. 1136/bmjopen-2013-003231

88. Sinn DH, Paik SW, Kang P, et al. Disease progression and the risk factor analysis for chronic hepatitis C. Liver Int. 2008;28(10):1363-1369. doi:10.1111/j.1478-3231.2008.01860.x

89. Tanaka H, Tsukuma H, Kasahara A, et al. Effect of interferon therapy on the incidence of hepatocellular carcinoma and mortality of patients with chronic hepatitis $\mathrm{C}$ : a retrospective cohort study of 738 patients. Int J Cancer. 2000;87(5):741749. doi:10.1002/1097-0215(20000901)87:5<741:: AID-IJC18>3.0.CO;2-B

90. Tateyama M, Yatsuhashi H, Taura N, et al. Alpha-fetoprotein above normal levels as a risk factor for the development of hepatocellular carcinoma in patients infected with hepatitis $\mathrm{C}$ virus. J Gastroenterol. 2011;46(1):92-100. doi:10. 1007/s00535-010-0293-6
91. Tseng CW, Chang TT, Tzeng SJ, et al. Association of sustained virologic response with reduced progression to liver cirrhosis in elderly patients with chronic hepatitis C. Clin Interv Aging. 2016;11:327-334. doi:10.2147/CIA.S97242

92. Yoshida H, Shiratori Y, Moriyama M, et al; IHIT Study Group. Interferon therapy reduces the risk for hepatocellular carcinoma: national surveillance program of cirrhotic and noncirrhotic patients with chronic hepatitis C in Japan. Ann Intern Med. 1999;131(3):174-181. doi:10.7326/0003-4819-131-3 199908030-00003

93. Yoshida H, Arakawa Y, Sata M, et al. Interferon therapy prolonged life expectancy among chronic hepatitis C patients. Gastroenterology. 2002;123(2): 483-491. doi:10.1053/gast.2002.34785

94. Yu ML, Lin S-M, Chuang W-L, et al. A sustained virological response to interferon or interferon/ribavirin reduces hepatocellular carcinoma and improves survival in chronic hepatitis C: a nationwide, multicentre study in Taiwan. Antivir Ther. 2006;11(8):985-994.

95. Younossi ZM, Stepanova M, Feld J, et al. Sofosbuvir and velpatasvir combination improves patient-reported outcomes for patients with HCV infection, without or with compensated or decompensated cirrhosis. Clin Gastroenterol Hepatol. 2017;15(3):421-430. doi:10.1016/j.cgh.2016.10.037

96. Younossi ZM, Stepanova M, Afdhal N, et al. Improvement of health-related quality of life and work productivity in chronic hepatitis $\mathrm{C}$ patients with early and advanced fibrosis treated with ledipasvir and sofosbuvir. J Hepatol. 2015;63(2): 337-345. doi:10.1016/j.jhep.2015.03.014

97. Younossi ZM, Stepanova M, Schwarz KB, et al. Quality of life in adolescents with hepatitis $C$ treated with sofosbuvir and ribavirin. J Viral Hepat. 2018;25(4):354-362. doi:10.1111/jvh.12830

98. Tomaszewski KJ, Deniz B, Tomanovich $P$, Graham CS. Comparison of current US risk strategy to screen for hepatitis $C$ virus with a hypothetical targeted birth cohort strategy. Am J Public Health. 2012;102(11):e101-e106. doi:10.2105/AJPH.2011. 300488

99. $\mathrm{Ng} \mathrm{X,} \mathrm{Nwankwo} \mathrm{C,} \mathrm{Arduino} \mathrm{JM,} \mathrm{et} \mathrm{al.}$ Patient-reported outcomes in individuals with hepatitis $C$ virus infection treated with elbasvir/grazoprevir. Patient Prefer Adherence. 2018;12:2631-2638. doi:10.2147/PPA.S172732

100. Younossi ZM, Stepanova M, Balistreri W, et al. Health-related quality of life in adolescent patients with hepatitis $C$ genotype 1 treated with sofosbuvir and ledipasvir. J Pediatr Gastroenterol Nutr. 2018; 66(1):112-116. doi:10.1097/MPG.

\section{4}

101. Azzaroli F, Accogli E, Nigro G, et al. Interferon plus ribavirin and interferon alone in preventing hepatocellular carcinoma: a prospective study on patients with HCV related cirrhosis. World J Gastroenterol. 2004;10(21):3099-3102. doi:10.3748/ wjg.v10.i21.3099

102. Bernardinello $E$, Cavalletto $L$, Chemello $L$, et al; TVVH Study Group. Long-term clinical outcome after beta-interferon therapy in cirrhotic patients with chronic hepatitis C. Hepatogastroenterology. 1999;46(30):3216-3222.

103. Bruix J, Poynard T, Colombo M, et al; EPIC3 Study Group. Maintenance therapy with peginterferon alfa-2b does not prevent hepatocellular carcinoma in cirrhotic patients with chronic hepatitis C. Gastroenterology. 2011;140(7): 1990-1999. doi:10.1053/j.gastro.2011.03.010

104. Fartoux L, Degos F, Trépo C, et al. Effect of prolonged interferon therapy on the outcome of hepatitis $C$ virus-related cirrhosis: a randomized trial. Clin Gastroenterol Hepatol. 2007;5(4):502-507. doi:10.1016/j.cgh.2006.10.016

105. Nishiguchi S, Shiomi S, Nakatani S, et al. Prevention of hepatocellular carcinoma in patients with chronic active hepatitis $\mathrm{C}$ and cirrhosis. Lancet. 2001;357(9251):196-197. doi:10.1016/SO140-6736 (00)03595-9

106. Valla DC, Chevallier M, Marcellin $P$, et al. Treatment of hepatitis $C$ virus-related cirrhosis: a randomized, controlled trial of interferon alfa-2b versus no treatment. Hepatology. 1999;29(6): 1870-1875. doi:10.1002/hep.510290616

107. Lok AS, Everhart JE, Wright EC, et al; HALT-C Trial Group. Maintenance peginterferon therapy and other factors associated with hepatocellular carcinoma in patients with advanced hepatitis $C$. Gastroenterology. 2011;140(3):840-849. doi:10.1053/ j.gastro.2010.11.050

108. Soga K, Shibasaki K, Aoyagi Y. Effect of interferon on incidence of hepatocellular carcinoma in patients with chronic hepatitis $C$. Hepatogastroenterology. 2005;52(64):1154-1158. 109. Falade-Nwulia $O$, Suarez-Cuervo $C$, Nelson DR, Fried MW, Segal JB, Sulkowski MS. Oral direct-acting agent therapy for hepatitis $C$ virus infection: a systematic review. Ann Intern Med. 2017;166(9):637-648. doi:10.7326/M16-2575

110. Jakobsen JC, Nielsen EE, Feinberg J, et al. Direct-acting antivirals for chronic hepatitis C. Cochrane Database Syst Rev. 2017;6:CD012143.

111. Cacoub P, Desbois AC, Comarmond C, Saadoun D. Impact of sustained virological response on the extrahepatic manifestations of chronic hepatitis C: a meta-analysis. Gut. 2018;67(11):2025-2034. doi:10.1136/gutjnl-2018-316234

112. Bang CS, Song IH. Impact of antiviral therapy on hepatocellular carcinoma and mortality in patients with chronic hepatitis C: systematic review and meta-analysis. BMC Gastroenterol. 2017;17(1):46. doi:10.1186/s12876-017-0606-9

113. Waziry R, Hajarizadeh B, Grebely J, et al. Hepatocellular carcinoma risk following direct-acting antiviral HCV therapy: a systematic review, meta-analyses, and meta-regression. J Hepatol. 2017;67(6):1204-1212. doi:10.1016/j.jhep. 2017.07.025

114. Indolfi G, Serranti D, Resti M. Direct-acting antivirals for children and adolescents with chronic hepatitis C. Lancet Child Adolesc Health. 2018;2 (4):298-304. doi:10.1016/S2352-4642(18)30037-3 115. Yek C, de la Flor C, Marshall J, et al. Effectiveness of direct-acting antiviral therapy for hepatitis $\mathrm{C}$ in difficult-to-treat patients in a safety-net health system: a retrospective cohort study. BMC Med. 2017;15(1):204. doi:10.1186/ s12916-017-0969-3

116. Su F, Green PK, Berry K, loannou GN. The association between race/ethnicity and the effectiveness of direct antiviral agents for hepatitis C virus infection. Hepatology. 2017;65(2):426-438. doi:10.1002/hep.28901 